\title{
DIE HANTERING VAN MOTIEWE IN DIE OU TESTAMENT
}

')

\author{
DS. J. A. LOADER
}

\section{INLEIDING.}

Wanneeer oor die Ou Testamentiese motiewe gehandel word, het ons te doen met 'n ontsaglik wye onderwerp. Dit gaan om niks anders nie as die eksegese van die Ou Testament - alleen onder die voorveronderstelling dat die eksegese beoefen word met gebruikmaking van die vormkritiese metode. Dit beteken dat ons eers kortliks sal moet definieer wat hierdie metode is en die terme waarvan hy gebruik maak, sal moet omskrywe. Daarna sal ons oor die Ou Testament se hantering van motiewe en oor ons hantering daarvan kan praat. Dit sal alleen baie sketsmatig gedoen kan word.

\section{GATTUNG EN MOTIEF - DIE VORMKRITIESE METODE:}

Hermann Gunkel was die groot aanvoorder van die vormkritiese metode. $\mathrm{Hy}$ het ingesien dat 'n mens die Ou Testament nie kan verstaan deur alleen te vra na die outeurskap en datering van sekere boeke nie, want die konsepsie van oorspronklike outeurskap het in die ou Ooste nie bestaan nie of alleen in 'n beperkte sin bestaan. Die outeurs was meer gebonde aan geykte vorme en kon dus hul persoonlike oorspronklikheid alleen in 'n beperkte ruimte uitoefen. Vorm eerder as outeur is dus die norm vir beoordeling en dienooreenkomstig moet hierdie literêre vorme aan 'n kritiese studie onderwerp word. Hoewel hierdie ontdekking later verabsoluteer is, het dit 'n kosbare resultaat opgelewer, naamlik die onderskeiding van talryke literêre tipes (Gattungen). Sulke Gattungen of literêre vorme is byvoorbeeld die regspreuk, orakel, novelle, geskiedsvertelling, klaaglied, danklied, liefdeslied, profetiese dreigrede, trooswoord en talle ander. Hulle is almal geykte vorme waarin die inhoud gegiet kan word. Hulle kan egter soms met mekaar vermeng word en ook voorkom in

3) Hierdie artikel is 'n poging om die resultate van verskeie Ou Testamentici se wetenskaplike arbeid in die diens van die kerklike prediking te implimenteer. Omdat die wyse van aanbieding nuut is, maar inhoudelik sterk afhanklik is van hierdie geleerdes se werk, is dit prakties nie moontlik om elke onderdeel en bewering te dokumenteer met 'n voetnota nie. Daarom word hier uitdruklik verwys na die arbeid van Hermann Gunkel (wat in die werk van Klaus Koch, "Was ist Formgeschichte", Neukirchen, 1967, behandel word), Gerhard von Rad (soos veral sigbaar in sy "Theologie des Alten Testaments", Munchen, 1957), en John Bright (,The Authority of the Old Testament", London, 1967). 
kontekste waar hulle nie verwag word nie. Daarom kan persoonlike oorspronklikheid en eienaardighede nie geheel-en-al buite rekening gelaat word nie. Die belangrike vraag wat die pad na die verstaan van die Ou Testament open, is volgens Gunkel: Watter Gattung het ons hier?

Hiermee saam moet nog 'n vraag gevra word: Wat is die Sitz im Leben van so 'n eenheid? Dit wil sê watter plek neem dit in in die struktuur van Israel se lewe? Is dit in die erediens waar iemand smeek, is dit by 'n skreiende sosiale euwel waar'n profeet kritiseer of in 'n wysheidskool waar 'n leraar onderrig gee, of waar?

Wanneer sulke formele arbeid afgehandel is, kan die inhoud ter sprake kom. Dit is eers hier waar motiewe aan die orde kom. Die motiewe is niks anders nie as die vleis en bloed wat die skelet van Gattungen vul nie. Geen wonder dat juis Gunkel ook 'n pionier van die sogenaamde Motivgeschichte was nie. ${ }^{2}$ ) 'n Motief is die uitdrukking van een gedagte. Vir ons doel kan ons sê dat motiewe die molekules is van die prediking van die Ou Testament. Byvoorbeeld: Wanneer Abram vir die Here 'n altaar bou, het ons te doen met die motief van die kultusinstelling (Gen. 12:7); en wanneer die Here later aan hom verskyn, is dit die motief van die teofanie (Gen. 17:1, 22). So kan ons voortgaan. Daar is, by wyse van spreke, soveel motiewe in die Ou Testament as wat daar verse is.

\section{DIE PROBLEEM VIR ONS HANTERING VAN DIE MOTIEWE.}

Wanneer ons hierdie veld betree, lê dit letterlik so wyd as die Heer se genade. Want as motiewe die uitdrukking is van elemente van die boodskap van die Ou Testament, moet hulle so ryk wees as die spreke van God self en van die Hebreeuse idioom. Een motief kan byvoorbeeld 'n geweldige uitbreiding in die Ou Testament hê, soms kernagtig by die naam genoem word, soms in lang gedeeltes uitgewerk word, soms veronderstel word; dit kan met ander motiewe gekombineer word, soms met ander saam in 'n organisasie eenheid verbind word; dit kan soms ander motiewe insluk en omvat (wat iets anders is as kombinasie); 'n motief kan soms 'n klein verbreiding in die Ou Testament hê en alleen vir' $n$ klein deel se verstaanbaarheid van belang wees; soms kan so 'n „,klein" motief baie belangrik wees; soms kan motiewe maklik herken word en soms is hul teenwoordigheid so gekamoefleer dat hulle maklik misgekyk word. So is die probleem dan dat daar ' $n$ totaal onoorsienbare mosaiek van moontlikhede is by die uitbreiding, beklemtonings, kombinasies en wisselwer-

2) Georg Fohrer, „Einleitung in das Alte Testament”, Heidelberg, 1965 , p. 27. 
king van verskillende motiewe in die Ou Testament. Al wat dus hier gebied kan word, is die skets van 'n aantal hooflyne en die illustrasie van 'n paar van hulle.

\section{VERSKILLENDE SOORTE MOTIEWE:}

Motiewe is nooit staties nie. Een motief kan nooit op sy eentjie staan nie. Daar moet altyd ander motiewe by wees om 'n sinvolle geheel te kan vorm, en die resultaat is altyd iets dinamies. Byvoorbeeld: Dit sou nie veel sê as Gen. 17 alleen die motief van die godsverskyning bevat het nie. God verskyn nie net aan Abram nie, maar die motiewe van opdrag, belofte, naamsverandering, aanbidding ensovoorts, dien almal om die geheel, wat 'n dinamiese gebéúre is, te bou. Dit illustreer ook dat elke passasie op eie meriete behandel moet word. Ons kan egter nou in die algemeen iets sê oor die verhouding van sulke motiewe tot mekaar.

Sommige motiewe staan veel meer voorop in die Ou Testament as andere en sommige meer voorop in gedeeltes van die Ou Testament as andere. Dit is nie wenslik om te praat van belangrike, en minder belangrike of onbelangrike motiewe in die Ou Testament nie. Gelukkiger terme vir sulke motiewe kan ontleen word aan die Genetika, naamlik dominante en resessiewe motiewe. 'n Resessiewe motief kan ook belangrik wees. As ons weer Gen. 17 vir die illustrasie gebruik, sal die woord „verbondsluiting” seker dadelik in die leser se gedagte kom. Dit is die dominante motief in die hoofstuk, maar dit is byvoorbeeld nie belangriker as die motief van die teofanie waar God self aan 'n mens verskyn nie.

(a) Eers, dan, kom daar dominante motiewe voor. 'n Voor. beeld is dié van die kultusvestiging. In die aartsvaderverhale kom die motief meermale voor. Maar by Sinai vind ons dit weer in magistrale vorm en die hele priesterlike wetgewing is 'n uitbouing daarvan. So gaan die motief deur die rigtertyd en die koningstyd tot by Esra en in die Psalms, Klaagliedere en elders tree dit uitdruklik of by wyse van veronderstelling op. 'n Motief kan ook dominant wees vir 'n enkele deel van die Ou Testament terwyl dit is die res terugtree of glad nie voorkom nie. Byvoorbeeld die ydelheidsmotief van Prediker is die allesoorheersende motief in elke woord wat hy sê en dus dominant, maar elders kom die motief nie meer voor nie.

Daarteenoor kom daar ook duisende resessiewe motiewe voor. Een voorbeeld sal voldoende wees. Die towertuinmotief van Hoogl. 4:12vv. het geen verbreiding in die Ou Testament nie. Hy tree heeltemal terug en is daarom resessief. Maar hy is nie onbelangrik nie, want hy het veel te sê vir die onderwerp waarom dit vir Hooglied gaan. 
Laastens moet daarop gelet word dat 'n dominante motief nie noodwendig oral waar hy voorkom 'n dominante posisie hoef in te neem nie. Byvoorbeeld die verbondsmotief wat so dominant by Abraham en Sinai is, kom in die Spreukeboek slegs in 2:17 voor - by wyse van 'n parentese in die konteks van die ontugtige vrou. In Spreuke neem hy 'n resessiewe posisie in, maar so gou as mens dit teen die agtergrond van die hele Ou Testament plaas, word dit duidelik dat jy te doen het met 'n oorheersende gedagte.

(b) Soos geblyk het, kom motiewe nooit geīsoleerd voor nie. Hulle assosieer altyd met mekaar om 'n geheel te vorm. Soms dra hierdie assosiasie 'n ad-hoc-karakter. Byvoorbeeld in Gen. 21 waar die motiewe van die bevoorregte mindere, jaloerse meerdere, verlorenheid en goddelike ingryping net bymekaar is omdat hulle vereis word om hierdie verhaal te kan vertel.

Maar soms kan die assosiasie van 'n aantal motiewe ook 'n chroniese karakter dra. Dan noem ons dit 'n tradisie. (Die term word hier in die enger, tegniese sin gebruik; in die wyer sin beteken dit bloot „oorlewering”). Byvoorbeeld: Die motiewe verkiesing, goddelike aanspraak, redding, verbondsluiting, kultusstigting en 'n horde resessiewe motiewe kom saam in die tradisie van die uittog uit Egipte. Hierdie tradisie het 'n geweldige uitbreiding in die Ou Testament en word dikwels met die noem van een of meer van sy dominante motiewe vermeld, soms veronderstel, soms uitgewerk of geīnterpreteer in verskillende grade van intensiteit en in verskillende Gattungen.

So 'n tradisie kan in later tye met veranderde omstandighede geherinterpreteer word. Deuterojesaja gebruik byvoorbeeld die Uittogtradisie om oor die terugkeer uit die ballingskap te praat. Presies die prediking van Exodus is in sy tyd aktueel en daarom vertolk en pas hy dit toe op die omstandighede van sy tyd.

(c) Laastens kan dit ook gebeur dat een hele tradisie met 'n ander een verbind word. Deuterojesaja is weer 'n voorbeeld daarvan. Naas die Uittogtradisie is daar ook 'n Skeppingstradisie. Wanneer hy die terugkeer wil aankondig, en hy die twee tradisies op mekaar in en so stel hy die terugkeer voor met die prediking van God wat sy volk uitlei en tegelyk sy skeppingswerk voortsit.

\section{VOORBEELDE VAN DIE UITLEG:}

By die illustrasie van die voorafgaande in die paragrawe wat volg, moet in gedagte gehou word dat daar nie nog aandag gegee kan word aan die vrae van die sogenaamde Literarkritik nie. Dit is uit die aard van die saak noodsaaklike voorarbeid omdat ons hier te doen het met literêre tekste, maar ons kan nie hier 
nog uitbrei oor die saak nie-dit sal nie meer onder die onderwerp ter sake val nie. Volledigheidshalwe kan egter net opgemerk word dat die vrae van die Literarkritik, wat handel oor die analise van boeke deur middel van die onderskeiding van dublette, weersprekings en steurende gedagteverbindings om die aandeel van outeurs, redakteurs, tyd en plek aan die ontstaan van sekere boeke vas te stel,") wel in berekening gebring is by die voorbeelde wat volg.

Verder moet daarop gelet word dat dit ons nie nou gaan bloot om 'n kritiese uitleg van sekere gedeeltes nie, maar om hul betekenis vir die kerklike prediking. Oor die teorie hiervan word ook nie gehandel nie; dit word sonder meer by die eksegese hieronder geïnkorporeer.

(a) Ex. 19:5 - 'n Dominante motief.

(i) Hier het ons te doen met die Literêre vorm (Gattung) van van die godsorakel. God is besig om 'n woord tot Israel te spreek deur Moses as middelaar. As ons dit vasgestel het, het ons die vorm waarin die inhoud gegiet word en staan ons op vaste grond.

(ii) In die teks kom daar meer as een motief voor, naamlik dié van gehoorsaamheid, verbond, verkiesing en aloutoriteit van God, terwyl dié van die godsverskyning veronderstel word. Dit is 'n uitstekende voorbeeld van hoe een motief deur andere gedra en ingevul word: Verkiesing is die grond vir die verbond en gehoorsaamheid is die voorwaarde vir die voortbestaan daarvan. Hoe belangrik die twee op sigself dan ookal is, hier is die dominante motief die verbond en die ander twee help om hom in te vul. Dus werk ons die verbondsmotief uit: 'n Kontrak waar een party die meerdere en 'n ander die mindere kan wees, soos ons uit die Hetitiese verdrae weet. ${ }^{4}$ ) Die meerdere gee die mindere beskerming en die mindere moet die meerdere se stipulasies gehoorsaam. As ons die motiewe so kan raaksien, merk ons op dat die preek nie uitvoerig moet gaan handel oor wat eienaarskap in die Ooste beteken of wat die almag van God alles inhou nie. Want die eersgenoemde is ' $n$ resessiewe motief om die inisiatief van God by die verkiesing tot die verbond aan te dui, en laasgenoemde is ' $n$ resessiewe motief wat aandui dat Hy die meerdere party in die verbond is. So kry die verbondsmotief hier deurligting van die ander motiewe.

(iii) Maar nou moet hierdie gegewens van die Ou Testament getransponeer word in die nuwe aeon, die bedeling van Christus. Daarmee word bedoel dat ons moet vasstel watter betekenis die Nuwe Testamentiese kerygma aan hierdie einste gedeelte van Gods Woord in die Ou Testament gee. Dit wil sê ons gaan

3) Sien Klaus Koch, op. cit., p. 87.

1) Sien Pritchard ed., ANET, Princeton 1955, p. 204. 
nie soek vir 'n teks in die Nuwe Testament wat hieroor handel nie; die verbondsmotief kom wel in die Nuwe Testament voor, maar in beginsel kon dit ook anders gewees het. Die Ou Testament word nie alleen dàn legitiem wanneer sy woorde in dié van die Nuwe Testament ingeforseer kan word nie - hy is legitiem. Die taak van die uitlegger is dan om die lig van Christus daaroor te laat val sodat die eie betekenis daarvan in die regte perspektief val. Dit sal by ons voorbeeld ter sake wees die inisiatief wat God, die meerdere, in Christus vir ons beskerming geneem het in sy vrye genade, en andersyds ons kontraktuele verpligting tot gehoorsaamheid. So pleeg ons met betrekking van motiefonderskeiding nie die gebruiklike soos-netso-sonde nie. Want nou kry die Ou Testament vir ons eksistensiële waarde en nie 'n maer paradigmatiese waarde nie. So sien die gemeente dat Exodus verkondig hoe God met ons handel en nie alleen dat Hy in die gryse verlede met Israel gehandel het nie.

\section{(b) Hoogl. 5:22vv. - Resessiewe motiewe.}

(i) Die Gattung is die stylvorm van die liefdeslied, dit wil sê waarin daar gehandel word oor die erotiese liefde of in die eerste of in die tweede of in die derde persone.

(ii) In hierdie passasie kom 'n hele aantal motiewe voor wat mekaar aanvul en oneweredig oor hele, meerdere of halwe verse strek. Dus sal mens hier perikoopuitleg moet toepas. 'n Aantal van die motiewe is die amator exclusus, afwysende meisie, soekvind, ekstase en andere. Hulle is in die Ou Testament resessief, maar hier baie belangrik. Al hierdie motiewe word omvat deur die dominante motief van Hoogl., naamlik erotiese samesyn. Hulle staan dus nie bloot naas mekaar nie, maar dien die prediking van hierdie oorheersende gedagte. Dus werk ons hom uit: Hoogl. praat onbevange en as't ware wêrelds oor eros, wat 'n geweldige prestasie vir die ou Ooste is. Want telkens is geslagtelikheid in die sakrale sfeer ingebring en in vrugbaarheidskultusse aangewend. Met ander woorde dit is iets goddeliks. Maar Hoogl. se sekulêre behandeling van die onderwerp ontmitologiseer seks van al sy afgodiese krag. So verkondig die boek al singende dat seks nie goddelik is nie, maar 'n gawe van God wat besing moet word.

(iii) Nou moet ons weer hierdie prediking vertaal in die terme van die nuwe aeon. Dit sou wees om die perspektief aan te toon dat die Vader van Jesus Christus geslagtelikheid aan die mense geskenk het, maar nie as 'n konkurrent vir sy Seun nie. Die prediking hiervan is vandag, dink ek, uiters aktueel. So gaan ons weer nie 'n geforseerde invalspoort deur 'n Nuwe Testamentiese teks in die kerk fabriseer nie. En so sal motiefondersoek ons ook 
beskerm daarteen dat ons van Christus 'n amator exclusus maak wat moedeloos die aftog moet blaas as sy gemeente Hom afwys.

(c) Pred. 1:2 - 'n Motief wat slegs in een boek dominant is.

(i) Die Gattung is 'n tipiese wysheidsvorm, naamlik die inleidingspreuk. Dikwels word 'n wysheidsversameling deur 'n inleidingsformulier voorafgegaan; dit is waarmee ons hier te doen het.

(ii) In hierdie teks vind ons net een motief - die niksheid van alles. Die feit dat dit in die inleidingsformulier staan, beteken dat die res van die boek met al sy baie motiewe onder hierdie opskrif staan. Hulle is almal manifestasies en illustrasies van hierdie grondkonsep. Anders as by Hoogl. waar 'n hele aantal motiewe een dominante motief opgevul en uitgebou het, is elkeen van die baie motiewe van Pred. ' $n$ illustrasie of manifestasie van die dominante motief. In die res van die Ou Testament raak hierdie grondgedagte van Pred. egter weg. Rykdom, arbeid, wysheid, ensovoorts is vir Pred. alles net wanhopige nietighede en geen mens kan met enige van sy pogings iets tot stand bring nie.

(iii) Nou moet ons die prediking van hierdie geweldige woord vir die kerk aantoon. Die ergste sou wees om te gaan moraliseer oor die nietigheid van rykdom, of die ydelheid van alles wat nie op die regte tyd plaasvind nie - soos Pred. 3 gewoonlik omgedolwe word. Alle menslike optrede is hopeloos, sê Pred. En in die tyd n.C. is dit net so waar as in die tyd v.C. Daarvan getuig die hele kerygma van Jesus en Paulus en die ander. As dit nie so was nie, sou die mense hulself kon help en geen Helper nodig gehad het nie. Maar juis omdat alle menslike pogings so uiters hopeloos is, het die mense 'n Helper broodnodig. Pred. diagnoseer so die pestende siekte van die mensdom, vir wie se genesing Christus gekom het. So toon Pred. hoe groot my ellende is, en sonder hierdie eerste deel van die Kategismus kan daar ook nie 'n tweede wees nie.

(d) Jes. 44:1-2 - twee tradisies in kombinasie.

(i) Die Gattung is die vorm van die profetiese trooswoord. Die profeet is aan die woord met 'n vertroosting wat van God na die volk gebring moet word.

(ii) Hier vind ons streng gesproke nie twee motiewe nie, maar twee volle tradisies terug, naamlik die tradisies van die Skepping en van die Uittog. Sulke tradisies, het ons vroeër gesien, bestaan uit talryke motiewe in assosiasie met mekaar. Maar omdat dit onmoontlik is om soveel gesigspunte op een plek bymekaar te bring, reduseer Deuterojesaja so 'n hele tradisie tot die minimumterme waarin daaroor gepraat kan word. So het ons hier dus twee volle tradisies wat in die vorm van enkele motiewe optree. Hulle is motiewe wat hierdie perikoop betref, 
maar gelaai met die rykdom van albei grootse tradisies. Deuterujesaja kombineer nou nie alleen die twee nie, maar hy interpreteer hulle ook. Dit gaan hom om die herstel van Israel uit die ballingskap. En dit verkondig hy deur te sê dat Gods skeppingsdaad nie ' $n$ afgehandelde saak is nie, maar nog op hierdie oomblik plaasvind: Uit die chaos van die ballingskap skep God vir sy volk nuwe orde. En net so lei Hy vandag sy volk uit Babel uit die slawehuis. En dit met al die veronderstellings waarvan die twee tradisies praat.

(iii) Dis gelukkig redelik eenvoudig om hierdie v.C.-terme in n.C.-terme te vertaal. Weer is dit nie nodig om by Hebreërs of by Paulus of êrens te gaan soek na 'n kapstok vir 'n soos-netso. vertolking nie. God het ons in Christus nuut geskep, en ons ook bevry van die slawerny - met al die veronderstellings wat dit dra. Selfs al kom die Skeppingstradisie en dié van die Uittog nie 'n enkele keer in die Nuwe Testament in verband met die verlossing van Christus voor nie, bly die prediking van die $\mathrm{Ou}$ Testament in hierdie lig nog net so wettig.

\section{SLOT.}

Dis iets totaal anders om uit die Ou Testament te preek as om te preek uit die Nuwe Testament waar 'n Ou Testamentiese gedeelte aangehaal word of waar spesifiek met Ou Testamentiese begrippe gewerk word. In so 'n geval is die transponering (vertaling) reeds gedoen en kan ons nie daaraan verander nie. ${ }^{5}$ ) Maar wanneer ons uit die Ou Testament preek, het ons nie die gesag om sy woorde en gedagtes in 'n Nuwe Testamentiese teks te gaan inforseer nie. Dit sou beteken dat ons albei laat buikspreek. Ons moet die totale lewenslig van die Nuwe Testament oor die Ou Testamentiese gedeelte laat skyn en so daardie sèlfde Ou Testamentiese gedeelte se aktuele boodskap vir òns laat hoor. Dis wat Bright bedoel met sy gelukkige uitdrukking „translate from one aeon to another, out of B.C. into A.D."')

Die beskuldiging word dikwels gemaak dat die kerk vandag besig is om die Godswoord in sy prediking te versmoor. Mense wil nie van dooie profete en Israel van die gryse verlede hoor nie. Is die kerk vry te spreek op hierdie aanklag? Is die prediking soos dit vandag geskied nie miskien grootliks verantwoordelik vir die wanopvatting dat die Ou Testament van dooie dinge praat nie? As ons die motiewe van die Ou Testament kan onderskei en reg en verantwoordelik hanteer, glo ek sal die moderne gemeente se oë weer oopgaan vir die lewenskragtigheid van die Godswoord in die Ou Testament.

5) Die struktuur van 'n preek uit Jes. 7:14 sal bv. totaal anders wees as dié van 'n preek uit Matt. 1:23.

6) Bright, op. cit., p. 183. 